\title{
Lateral Ventricular Epidermoid with Severe Coarse Tremor and Weakness in Opposite Limbs: A Rare Case Report
}

FORHAD HOSSAIN CHOWDHURY, ${ }^{1}$ MOHAMMOD RAZIUL HAQUE, ${ }^{2}{\mathrm{KHANDKAR} \mathrm{ALI} \mathrm{KAWSAR,}{ }^{1} \text { MOMTAZUL HAQUE}}^{1}$

\begin{abstract}
:
Intracranial epidermoid tumor is rare and intraventricular epidermoid is further rare. Occurrence of epidermoids is common in posterior carnial fossa. Fourth ventricle is relatively common site for intraventricular epidermoid. Epidermoid tumor in lateral ventricle is very rare. Such a tumor presenting with severe progressive coarse tremor and weakness in opposite side of the body probably had never been reported. The epidermoid was removed by endoscope assisted microsurgical technique. Post operatively patient recovered from tremor limbs weakness. Here we report a very rare case of lateral intraventricular epidermoid with tremor and weakness in opposite limbs as well as surgical techniques with short review of related literatures.
\end{abstract}

Key Words: Lateral ventricle, intraventricular epidermoid, coarse tremor, limb weakness, extra pyramidal symptoms (EPS).

\section{Introduction:}

$0.2 \%$ to $1 \%$ of all primary intracranial tumors are epidermoid tumor. Intracranial epidermoid tumors are histologically benign, slow-growing, congenital neoplasm of the central nervous system. They usually present in adults and are commonest in the cerebellopontine angle or suprasellar region protruding in the subarahnoid space. Epidermoids occurring within the lateral ventricles are very rare. ${ }^{1}$ They are slow growing, and the clinical presentation is non-specific like deterioration of mental functions. ${ }^{1,2}$ To our knowledge, there is less than 10 reports of epidermoids located in lateral ventricles. ${ }^{1,2}$ Probably lateral ventricular epidermoid tumor with severe coarse tremor is not published in literature. Here we report a very rare case of lateral intraventricular epidermoid with tremor and weakness in opposite limbs with surgical techniques.

\section{Case report:}

\section{Case description:}

A right handed sixteen year old young girl presented with headache and progressively increasing right sided limbs tremor for last four year. Her headache was occasional, intermittent, global and not associated any visual disturbance, vomiting, unconsciousness or convulsion. Her tremor was initially postural and fine but later increased in intensity and became postural as well as intentional. Tremor also became

1. Neurosurgeon, Department of Neurosurgery, Dhaka Medical College, Dhaka.

2. Associate Professor, Department of Neurosurgery, Dhaka Medical College, Dhaka.

3. Neurosurgeon, department of Neurosurgery, Dhaka Medical College, Dhaka.

4. Department of Neurosurgery, Dhaka Medical College, Dhaka. Correspondence: Dr. Forhad Hossain Chowdhury, FCPS. Neurosurgeon, Department of Neurosurgery, Dhaka Medical College Hospital, Dhaka, Bangladesh. Phone +8801711949570, Fax-00887201239, E-mail: forhadchowdhury74@yahoo.com. severely coarse for which she was not able to write. Tremor was confined to her right upper and lower limb, more marked in right upper distal limb. Last one year she also developed right sided hemiparesis. Muscle power in right side of the limbs was MRC grade $4 / 5$. DTR on right side were increased and right sided planter reflex was extensor. Her higher psychic functions with speech and memory were intact. Cranial nerves including fundoscopy were normal. Her autonomic functions were also intact. MRI brain showed a space occupying mass in left lateral ventricular body, trigone, part of occipital and frontal horn that enlarged the left lateral ventricle and extended to opposite side by crossing and compressed the right lateral ventricle (Figure1\&2). It also

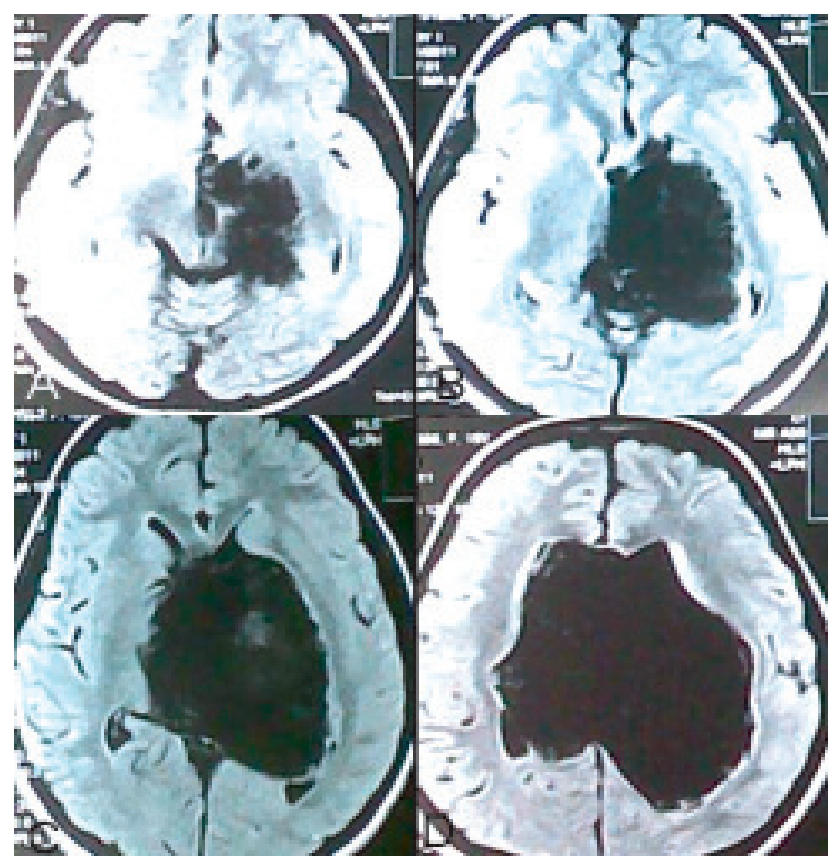

Fig.-1: $A, B, C \& D$ - Preoperative MRI of brain FLAIR axial images showing epidermoid tumor of left lateral ventricle pressing over thalamus and left midbrain. 
effaced the third ventricle and put pressure over both thalamus, caudate nucleus, left upper mid brain. It was hypointense in $\mathrm{T} 1 \mathrm{~W}$ images, hyper intense in $\mathrm{T} 2 \mathrm{~W}$ images and in FLAIR it mostly hypointense except its peripheral zone and capsule where in is partly mild to moderately hyperintense in some areas. FLAIR and DW (quality of DW images were poor) images failed to differentiate whether it was epidermoid cyst, arachnoid cyst or CSF.

\section{Operative techniques:}

A left sided fronto-parietal craniotomy was done near the midline without exposing superior saggital sinus. $2 / 3^{\text {rd }}$ of craniotomy was placed anterior to coronal suture. The skin incision was ' $U$ ' shaped with a base on the lateral side. Dura was opened with 'U" shaped flap based toward medially. Superior frontal gyrus, middle frontal gyrus and superior frontal sulcus were identified. After necessary cortical venous mobilization by arachnoid dissection right lateral ventricle was reached through trans -superior frontal sulcus approach (Figure3A,B). After draining of rush ventricular CSF pearly white materials of epidermoid came in view. After draining of CSF, the brain became very relaxed. With microscopic

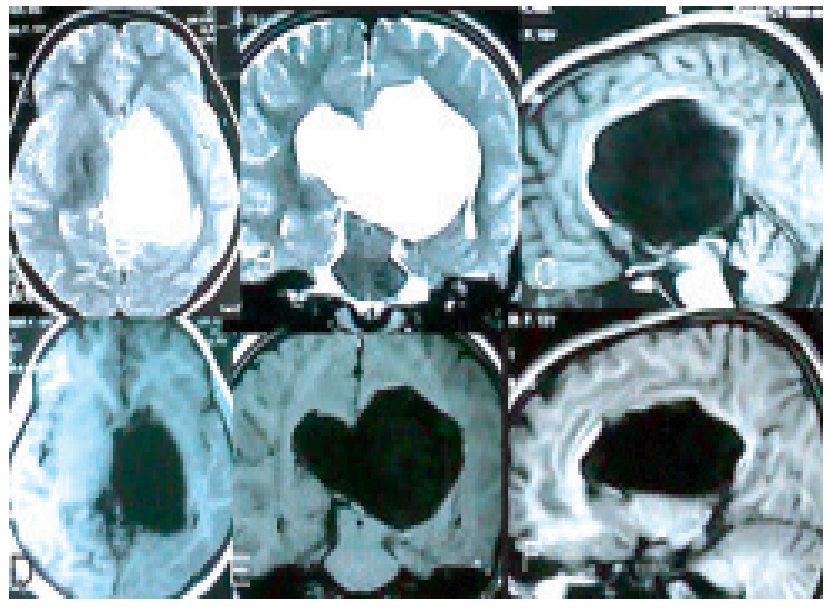

Fig.-2: Preoperative MRI of brain; T2W images, $A$ - axial, $B$ - Coronal image; TIW Images, $C \& F$ - Saggital, $D$ axial, $F$-Coronal images showing the left lateral ventricular epidermoid tumor.

and self retaining retractor manipulation we removed the tumor near totally (Figure 3C,D,E\&F). We left the part capsule in some places where it seemed that capsule was firmly adhering to ventricular wall and related structures. During operation we reliably identified the left surface of septum pellucidum with septal vein (Figure 3F), part of choroids plexus and foramen of Monro (left). But poaterior part of septum and choroids plexus could not be seen due to firm attachment of capsule. At the end of operation we used neuro-endoscope to inspect the operation sites for any residual tumor and residual part was removed with help of endoscope (Figure 4 A, B, C \& D).

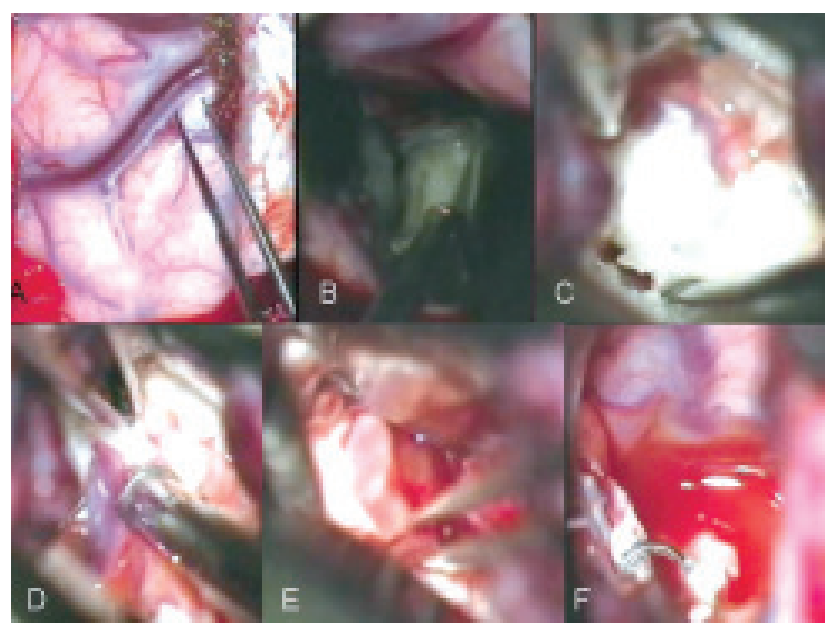

Fig.-3: Peroperative pictures. A - Arachnoid dissection in superior frontal sulcus for mobilization of cortical vein. $B$ Transsulcal entrance into left lateral ventricle. $C, D \& F$ peroperative pictures of microsurgical removal of epidermoid tumor.

\section{Postoperative course:}

We used inj. Dexamethasone and inj. Phenytoin peroperatviely and post operatively to prevent chemical meningitis and seizure respectively. But two hours after patient developed generalized seizure and that was managed

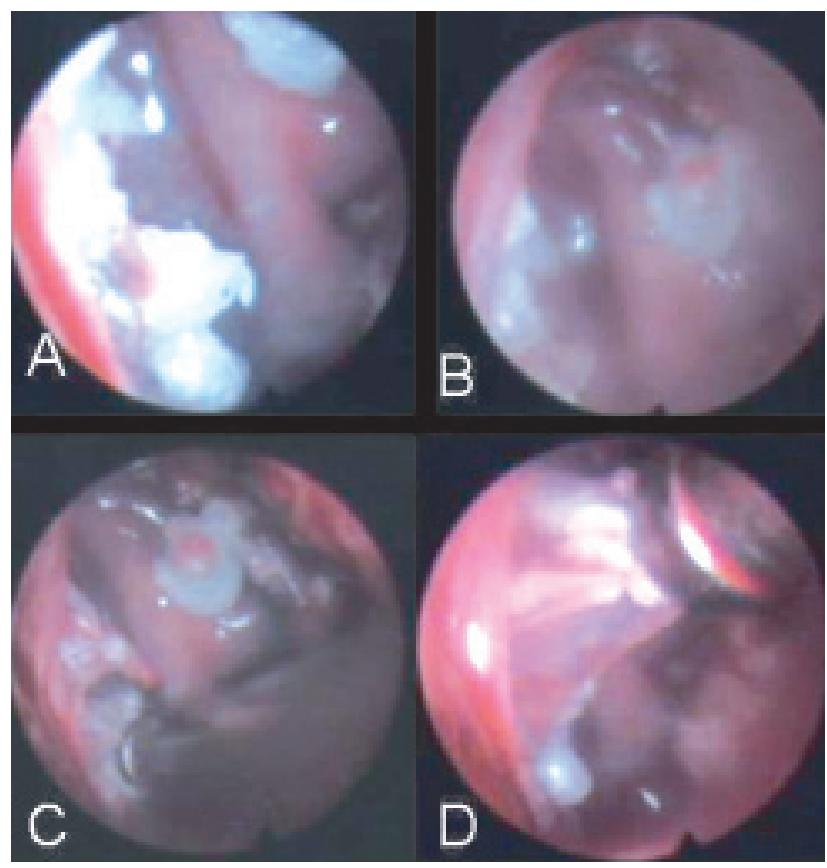

Fig.-4: $A, B \& C$ - Pictures of neuro-endoscopic checking for residual tumor. $D$ - removal of small residual tumor under endoscopic vision. 
by i.v. bolus inj phenytoin followed by maintenance of i.v. drip of inj phenytoin for 96 hours. Immediate CT scan showed no haematoma, mass effect or hydrocephalus. Rest of the post operative period was uneventful. Her hemiparesis improved to normal by three weeks after operation. Tremor intensity began to reduce immediately after operation. By the end of six months after operation she returned to her school and was able to write comfortably but there was mild postural tremor persisted in her right upper limb. She was put on postoperative anticonvulsant for two years as she had an immediate post operative seizure. Two weeks after operation post operative CT scan showed opening up of frontal horn, occipital horn of left lateral ventricle, right lateral ventricle and third ventricle. There was also evidence of an intact right sided wall of cavum septum pellucidum, (Figure5). But there was still residual dead space in tumor area with deformed left lateral ventricular wall. Histopathological examination of tumor tissue reported epidermoid tumor.

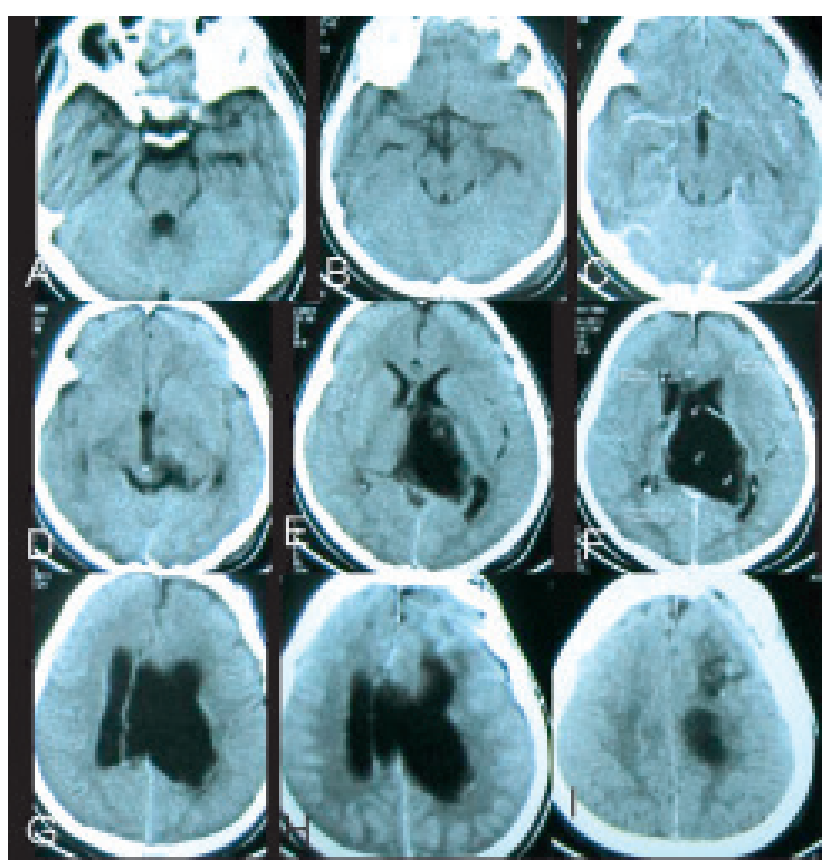

Fig.-5: $A, B, C, D, E, F G, H \& I-T w o$ weeks after operation post operative CT scan(serial axial sections) showed opening up of frontal horn, occipital horn of left lateral ventricle, right lateral ven

\section{Discussion:}

Approximately $60 \%$ of all intracranial epidermoids occur in cerebello-pontine angle (CPA). Among the intraventricular epidermoids $4^{\text {th }}$ ventricular epidermoids are most common. ${ }^{3}$ Epidermoids occurring within the lateral ventricles is rare. The lesions are of developmental etiology, due to migration of epiblast inclusion at the time of formation of the cerebral vesicle. Generally seen in the fifth decade, but they have also been observed in the pediatric age group. ${ }^{2}$ Signs and symptoms of epidermoid cysts are due to gradual mass effect, with presentation including: headaches (most common), cranial nerve deficits, cerebellar symptoms, seizures, raised intracranial pressure. Recurrent aseptic meningitis is uncommon but recognized, similar to the less common dermoid cyst. ${ }^{3}$ Lateral ventricular epidermoids are slow growing, and presentation is non-specific in the form of deteriorating mental functions. ${ }^{2}$ The major differential diagnosis for a epidermoid cyst are arachnoidal cysts, hamartomatous lipomas, dermoid cysts, cystic neoplasm etc. ${ }^{4.5}$ They can usually be differentiated by CT scan or MRI images of brain. Conventional MR images sometime cannot reliably be used to distinguish epidermoid tumors from arachnoid cysts since both lesions are very hypointense relative to brain parenchyma on T1-weighted MR images and very hyperintense on T2- weighted images. In contrary, FLAIR and DW sequences can successfully be used for diagnosis of epidermoid cysts by revealing its solid nature. ${ }^{1,6,7}$ But in lateral ventricular epidermoid, MRI is suggestive of a cystic lesion, and is confirmed to be a typical epidermoid within the lateral ventricle at operation, often having a connection to the midline through the choroidal fissure. ${ }^{2}$ In our case, we failed to understand preoperatively whether the lesion was epidermoid or not even in FLAIR and DW images of MRI. Epidermoid cyst was confirmed during operation. Hydrocephalus is said to be uncommon because of the long-standing nature of the lesion and also because CSF can permeate through the crevices of the lesion. $^{3}$

The cysts should be excised with no additional morbidity. ${ }^{2}$ The surgical approaches for such a lesion is trans cortical (Transgyral-middle frontal gyrus, transsulcul-trans superior forntal sulcul) and transcollosal approach. We prepared transsuperior frontal sulcul approach for less manipulation of veins and less destruction of cerebral cortex. The surgical approach is generally determined by the location and the extent of the lesion. There is a controversy regarding the extent of removal. Although the aim of surgery is complete removal but only few authors advocate total removal of the tumor. ${ }^{8,9,10}$ A conservative approach with decompression and the removal of the non-adherent portion of the capsule has been suggested by many authors. ${ }^{3,11,12}$ Chemical meningitis can occur by spillage of the cyst contents during operation, which usually is transient and self-limiting ${ }^{10}$ and can be managed successfully with steroids. Histopathology reveals typical stratified squamous epithelium. ${ }^{2}$ 
Nevertheless, epidermoids are often the most troublesome to cure because of their insinuating growth which make it difficult for radical excision. ${ }^{10}$ It is not surprising that, prior to the microsurgical era, operative mortality ranged from $20 \%$ to $57 \% .{ }^{12}$ But now a days, surgery induced mortality is very low. Partial removal of a lesion leads to recurrence, which often occurs after a prolonged period. ${ }^{8,11}$ As the hypodense areas revealed by $\mathrm{CT}$ persist for a prolonged period, even after complete removal of the tumor, possibly because of a long-standing deformation of the neural structures, a diagnosis of recurrence at an early stage is often not possible. MRI is useful to diagnose an early recurrence. ${ }^{9}$

Epidermoid can occur not only in lateral ventricle but also in cavum pellucidum. ${ }^{13}$ In our case, post operative CT showed there was also evidence of an intact right sided wall of cavum septum pellucidum and absent of left sided cavum wall. But during operation we identified the part of septum pellucidum with septal vein and part of choroids plexus on left side that might suggest, tumor was in lateral ventricle but it might be an epidermoid originated from cavum pellucidum that extended in lateral ventricle.

Although there is reports of tremor from intracranial lesion such as meningioma, intraventricular and thalamic gliomas ${ }^{14,15}$ but probably there is no report of tremor caused by intraventricular epidermoid. Such tremors can be explained by pressure or infiltration of ventroanterior and ventrolateral thalamic nuclei, dentate rubrothalamic tract ${ }^{15,16}$ and pressure on midbrain (red nucleus). Borremans JJ et al ${ }^{17}$ reported patients who developed hemichoreahemiballism ipsilateral to and intraventricular cyst after resection of a meningioma of the lateral ventricle while under medication with phenytoin. Magnetic resonance imaging demonstrated distortion of the upper brainstem and diencephalon compatible with functional involvement of the contralateral subthalamic nucleus. The movement disorder disappeared after drainage of the cyst. Hemichorea and hemiballism have been reported to be associated with ipsilateral cerebral lesions in a rare cases. ${ }^{17}$ Most of the hemiplegia- extra pyramidal symptoms (EPS) syndromes are caused by hemispheric lesions including tumors, but there are reported etiologies with central and basifrontal lesions like pituitary adenoma and craniopharyngioma can cause such syndromes. ${ }^{18,19}$

In our patient we think, hemiparesis was due to pressure over corona radiata, internal capsule and upper midbrain but it might be conditional effect from dyskinetic movement disorder. Regarding the pathogenesis of contralateral hemiparesis with extrapyramidal symptoms, the former is often considered a conditional effect from dyskinetic movement disorderes as reported by Krauss et al. ${ }^{20}$

EPS syndromes may be self limiting are usually managed symptomatically with neuorlectics (haloperidol, fluphanazine), dopaminergic antagonist (tetrabenazine), GABAergic (gabapntine, valproate) and benzodiazepines (diazepam, pimozide) $)^{21,22,23}$ but nontumoral intractable cases may need surgical treatment (i.e. DBS, thalamotomy, pallidotomy). ${ }^{24,25,26} \mathrm{EPS}$ syndromes associated with surgical lesion (cavernoma, angioma, tumor) are less responsive to drugs treatment, surgical removal of lesion is usually needed and may be curative in benign lesion. ${ }^{27,28,29}$ Definitive treatment with fetal cell transplantation or neuro-stem cell transplantation is still in infancy. ${ }^{30,31}$

\section{Conflict of Interest : None}

\section{References:}

1. Franko A, Holjar-Erli I, Mileti D. Lateral ventricle epidermoid. Radiol Oncol. 2008;42(2): 66-68.

2. Bhatoe HS, Mukherji JD, Dutta V. Epidermoid tumor of the lateral ventricle. Acta Neurochir (Wien). 2006; 148(3): 339-342.

3. de Souza CE, de Souza R, Da Costa S, Sperling N, Yoon TH, Abdel Hamid MM, Sharma RR, Goel A: Cerebellopontine angle epidermoid cysts: A report on 30 cases. J Neurol Neurosurg Psychiatry.1989;52:986-990.

4. Osborn AG, Preece MT. Intracranial cysts: radiologicpathologic correlation and imaging approach. Radiology. 2006;239:650-664.

5. Tancredi A, Fiume D, Gazzeri G. Epidermoid cysts of the fourth ventricle: very long follow up in 9 cases and review of the literature. Acta Neurochir. 2003;145:905-911.

6. Chen S, Ikawa F, Kurisu K, Arita K, Takaba J, Kanou Y. Quantitative MR evaluation of intracranial epidermoid tumors by fast fluid-attenuated inversion recovery imaging and echo-planar diffusion-weighted imaging. AJNR Am J Neuroradiol. 2001;22:1089-1096.

7. Tsuruda JS, Chew WM, Moseley ME, Norman D. Diffusion weighted MR imaging of the brain: value of differentiating between extraaxial cysts and epidermoid tumors. AJNR Am J Neuroradiol. 1990;11:925-931.

8. Altschuler EM, Jungries CA, Sekhar LN, Jannetta PJ, Shertak PE: Operative treatment of intracranial epidermoid cysts and cholesterol granulomas: Report of 21 cases. Neurosurgery. 1990;26:606-614.

9. Long DM: Intracranial epidermoid tumors, in Apuzzo MLJ (ed): Brain Surgery: Complication Avoidance and 
Management. New York, Churchill Livingstone. 1993:669688.

10. Yasargil MG, Abernathey CD, Sarioglu AC: Microsurgical treatment of intracranial dermoid and epidermoid tumors. Neurosurgery. 1989;24:561-567.

11. Lunardi P, Missori P, Innocenzi G, Gagliadi FM, Fortuna FM: Long-term results of surgical treatment of cerebellopontine angle epidermoids. Acta Neurochir (Wien). 1990;103:105-108.

12. Samii M, Tatagiba M, Piquer J, Carvalho GA: Surgical treatment of epidermoid cysts of the cerebellopontine angle. J Neurosurg. 1996;84:14-19.

13. Epidermoid cyst of the cavum septum pellucidum. Bikmaz K, Dinc C, Cakabay M, Iplikcioglu AC. Acta Neurochir (Wien). 2007;149:1271-1272.

14. El'ner AM, Gabibov GA, Lobkova EF.Unusual tremor in a patient with a local lesion of the brain. Zh Nevropatol Psikhiatr Im S S Korsakova. 1984;84(4):530-533.

15. Rajput DK, Mehrotra A, Srivastav AK, Kumar R, Mahapatra AK. Bilateral thalamic glioma in a 6-year-old child. J Pediatr Neurosci. 2010;5:45-48.

16. Behari S, Vaid V, Singhal N, S Reddy J, Benergi D. Bilateral astrocytomas: Clinicoradiological characteristic and endoscopic management. Pan Arab J Neurosurg. 2009;13: 98-103.

17. Hemichorea-hemiballism associated with an ipsilateral intraventricular cyst after resection of a meningioma. Borremans JJ, Krauss JK, Fanardjian RV, Seeger W. Parkinsonism Relat Disord. 1996;2:155-159.

18. A case report on pituitary macroadenoma presented as hemichorea hemiballism syndrome.Erer S, Yilmazlar S, Zarifoglu M, Guclu M. Neurol Sci. 2008;29:289-290.

19. Barthez MA, Billard C, Santini JJ. Abnormal movement disclosing craniopharyngioma. Apropos of 2 cases. Arch Fr Pediatr. 1985;42:787-789.
20. Krauss JK, Pohle T, Borremans JJ.Mov Disord. Hemichorea and hemiballism associated with contralateral hemiparesis and ipsilateral basal ganglia lesions. 1999;14:497-501.

21. Klawans HL. Chorea. Can J Neurol Sci. 1987;14(3 Suppl):536-540.

22. Axley J. "Rheumatic choreia controlled with haloperidol". The Journal of Pediatrics1972;81:1216-1217.

23. Yakinci C, Durmaz Y, Korkut M, Aladag A, Onal C, Aydinli M. Cavernous hemangioma in a child presenting with hemichorea: response to pimozide. J Child Neurol. 2001;16:685-688.

24. Thompson TP, Kondziolka D, Albright AL. Thalamic stimulation for choreiform movement disorders in children. Report of two cases. J Neurosurg. 2000;92:718-721.

25. Krauss JK, Loher TJ, Weigel R, et al. Chronic stimulation of the globus pallidus internus for treatment of non-dYT1 generalized dystonia and choreoathetosis: 2-year follow up. J Neurosurg. 2003;98:785-792.

26. Moro E, Lang AE, Strafella AP, et al. Bilateral globus pallidus stimulation for Huntingtons disease. Ann Neurol. 2004;56:290-294.

27. Hemichorea due to a cavernous angioma of the caudate. Case report of an aged patient. Carella F, Caraceni T, Girotti F.Ital J Neurol Sci. 1992;13:783-785.

28. Donmez B, Cakmur R, Uysal U, Men S. Putaminal cavernous angioma presenting with hemichorea. Mov Disord. 2004;19:1379-1380.

29. Kimura A, Mitake S. Repeated hyperglycemic hemichorea in a patient with venous angioma in the putamen. Rinsho Shinkeigaku. 2001;41:113-116.

30. Bachoud-Levi AC, Gaura V, Brugieres P, Lefaucheur JP, Boisse MF, Maison P, et al. Effect of fetal neural transplants in patients with Huntingtons disease 6 years after surgery: a long-term follow-up study. Lancet Neurol. 2006;5:303-309.

31. Keene CD, Sonnen JA, Swanson PD, Kopyov O, Leverenz JB, Bird TD, et al. Neural transplantation in Huntington disease: long-term grafts in two patients. Neurology. 2007;68:2093-2098. 